\title{
Low prevalence of myopia among school children in rural China
}

\author{
Chen-Wei Pan ${ }^{1}$, Rong-Kun Wu', Jun $\mathrm{Li}^{2}$ and Hua Zhong ${ }^{3^{*}}$
}

\begin{abstract}
Background: We aim to assess the prevalence of myopia in Chinese school children with low educational pressure and explore which factors could explain the differences in prevalence between generations.

Methods: A school-based epidemiologic study including 2432 grade 1 and 2346 grade 7 students was conducted from 2016 in rural areas of China. Each participant's refractive status was measured before and after cycloplegia using an autorefractor and axial length (AL) was measured using an IOL Master. The questionnaires were completed by the parents or legal guardians of the children to collect detailed information regarding risk factors. Myopia was defined as spherical equivalent less than - 0.50D.

Results: Grade 7 students had a higher prevalence of myopia (29.4\% vs. 2.4\%; $P<0.001$ ) and high myopia (0.4\% vs. 0.1\%; $P<0.001)$ compared with grade 1 students. Grade 7 students also had longer ALs (23.50 mm vs. $23.37 \mathrm{~mm} ; p=0.004)$ after adjusting for the effect of gender, height and other myopia-related risk factors. Adjustment for time spent on reading and writing after school per day led to a reduction in the excess prevalence of myopia in grade 7 students by $15.1 \%$. In addition, adjustment for time outdoors reduced the excess prevalence of myopia in grade 7 students by $33.4 \%$.
\end{abstract}

Conclusions: We reported a relatively lower prevalence of myopia in school students in rural China, suggesting that Chinese may not have a genetic predisposition to myopia and environmental factors may play a major role in the development of school myopia in Chinese children.

Keywords: Myopia, Chinese, Prevalence, Risk factors

\section{Background}

Myopia is a worldwide health concern and its burden has increased rapidly in recent years [1-3]. Several studies have revealed significant ethnic variations in the prevalence of myopia and it is always reported that myopia is more prevalent in Chinese compared with other ethnic groups [4-7]. Thus, research regarding the epidemiology of myopia in Chinese population is a major interest to global myopia investigators.

The reasons underlying the observed disparities in myopia prevalence between Chinese and other ethnic groups remain unclear [8]. Ethnicity is a proxy measure for the differences in both genetic biomarkers and environmental exposures such as the intensity of schooling, near work activities, time outdoors, and other lifestyle factors $[9,10]$. In the past decades, genetic studies including linkage analyses,

\footnotetext{
*Correspondence: zhoculist@163.com

${ }^{3}$ Department of Ophthalmology, the First Affiliated Hospital of Kunming

Medical University, 295 Xi Chang Road, Kunming 650032, China

Full list of author information is available at the end of the article
}

candidate gene and genome-wide association studies, and next-generation sequencing studies have substantiated the gene mapping for myopia in Chinese [11-16]. One may hypothesize that Chinese may have a genetic predisposition to myopia. An alternative hypothesis is that environmental factors play a major role as Chinese culture emphasizes on very early educational achievements and passing examinations. Therefore, Chinese children may have devoted more time to rigorous learning and less time in outdoor play in their early years of life compared their counterparts of other ethnicities.

Comparison of the prevalence of myopia between those who have just started schooling and those who have completed several years of education living in the same region may help to elucidate how environmental exposures could explain the differences in myopia prevalence between generations. In this study, we reported the prevalence of myopia in two samples of Chinese school children (grade 1 students and grade 7 students)

(c) The Author(s). 2018 Open Access This article is distributed under the terms of the Creative Commons Attribution 4.0 International License (http://creativecommons.org/licenses/by/4.0/), which permits unrestricted use, distribution, and 
in a rural county in China, where educational pressure such as schooling systems and parental expectation on academic achievements is less intensive than many of the other Chinese communities. We also explored which factors could explain the differences in prevalence between the two samples.

\section{Methods}

\section{Study population}

The Mojiang Myopia Progression Study is a school-based cohort study in rural China. The study protocol has been described elsewhere [17-19]. The study included two samples: elementary school grade 1 students and middle school grade 7 students. Elementary school grade 1 students would be followed until they entered middle schools and middle school grade 7 students would be followed until they entered high schools. Such a study design would facilitate the follow up of the samples and possibly reduce the loss-to-follow-up rate considering the current Chinese schooling system. The baseline survey was conducted in 2016 and all the participants were followed annually. Mojiang is a small county with a population of 0.36 million in Southwestern China. The compulsory schooling system is well executed in Mojiang and school-based samples are highly representative of the local population.

We invited all the grade 1 students from elementary schools and grade 7 students from middle schools in Mojiang to participate in this study. The students roster was provided by each school's principal to ascertain the eligibility of the study participants. Students who had been living in Mojiang for at least 1 year and would live there for at least 4 years were included. Before the study, school principals had contacted the parents asking about their plan. A cell phone message was sent to the parents to invite them to participate in the study. Telephone calls were made if the parents did not respond to the cell phone message. In the end of the study, a total of 2432 (response rate: 90.2\%) grade 1 students and 2346 (response rate: $93.5 \%$ ) grade 7 students participated in the baseline survey.

The Mojiang Myopia Progression Study was approved by the Institutional Review Board of Kunming Medical University. Written informed consents was obtained from at least one parent or legal guardian of each participant.

\section{Refractive error and ocular biometry measurement}

Refractive error was measured after cycloplegia using an autorefractor (RM-8000; Topcon Corp., Tokyo, Japan). Myopia was defined as spherical equivalent (SE) less than -0.50 diopter (D). Ocular biometric parameters such as axial length (AL) were measure using an IOL Master (Carl Zeiss Meditec AG, Jena, Germany).

\section{Questionnaires}

The World Health Organization (WHO) myopia risk factor questionnaire was used in this study [20-23]. The questionnaires were completed by the parents or legal guardians of the children. We collected detailed information regarding socioeconomic status, parental education, parental history of myopia, medical history, time spent on reading and writing, time spent on watching $\mathrm{TV}$, time spent on playing computers and outdoor activities.

\section{Statistical analysis}

Data were analyzed using a commercial statistical software (Statistical Package for Social Science, SPSS V16.0; SPSS Inc., Chicago, IL). As the correlation of SEs $(r=0.90)$ and ALs $(r=0.98)$ between two eyes was high $(r=0.90)$ and the results of analysis in both eyes were similar, only data for the right eye are presented in this paper. Distribution for refractive error and ocular biometric parameters was tested for normality with the Kolmogorov-Smirnov test and were considered significantly different from normal when $P$ value was less than 0.05 . Prevalence were estimated with mixed models being fitted to adjust for clustering within schools. Where cluster effects were not significant, $t$-tests and normal linear regression were used. All confidence intervals (CIs) are 95\%.

To evaluate the extent that myopia-related lifestyle risk factors may explain the excess prevalence of myopia in grade 7 compared with grade 1 students, we estimated the percentage reduction in odds associated with adjustment for myopia-related lifestyle risk factors according to the following formula: (Ra-Rb)/(Ra-1) x 100, where $\mathrm{Ra}$ is the odds ratio (OR) of myopia in grade 7 compared with grade 1 students, adjusted for gender only (reference model), and $\mathrm{Rb}$ is the OR in models after additional adjustment for myopia-related lifestyle risk factors. ORs were generated from logistic regression models, where myopia were treated as binary outcome measures. This method has been reported in previous publications $[24,25]$.

\section{Results}

Two thousand four hundred thirty two grade 1 and 2346 grade 7 students were included in the analysis and their mean ages were 7.7 and 13.8 years for grade 1 and 7, respectively. There were more girls among grade 7 students compared with grade 1 students ( $48.3 \%$ vs. $44.8 \%)$. Comparison of myopia-related variables between the two samples indicated that grade 7 students had a greater body mass index $(P<0.001)$, had less myopic parents $(P<0.001)$, spent more time watching TV $(P=0.001)$ and playing computers $(P<$ $0.001)$ and spent less time outdoors $(P<0.001)$ (Table 1). 
Table 1 Characteristics of myopia-related variables among grade 7 and grade 1 samples

\begin{tabular}{llll}
\hline Variables & Grade 1 Sample & Grade 7 Sample & $P$ \\
\hline Girls(\%) & $1089(44.8)$ & $1133(48.3)$ & 0.015 \\
BMI, kg/m2 (SD) & $15.3(2.5)$ & $18.9(2.7)$ & $<0.001$ \\
$\begin{array}{l}\text { Parental myopia(\%) } \\
\text { Time on reading and }\end{array}$ & $0.952(14.5)$ & $129(5.6)$ & $<0.001$ \\
$\begin{array}{l}\text { writing per day after } \\
\text { school, hours (SD) }\end{array}$ & & $0.93(0.67)$ & 0.38 \\
$\begin{array}{l}\text { Time on computer } \\
\text { per day, hours (SD) }\end{array}$ & $1.42(1.30)$ & $0.90(0.90)$ & $<0.001$ \\
$\begin{array}{l}\text { Time outdoors } \\
\text { per day, hours (SD) }\end{array}$ & $2.60(0.19)$ & $1.34(1.03)$ & $<0.001$ \\
$\begin{array}{l}\text { Time on watching TV } \\
\text { per day, hours (SD) }\end{array}$ & $0.79(0.43)$ & $1.38(0.91)$ & 0.001 \\
\hline
\end{tabular}

The distributions of cylindrical values, spherical values, SEs and ALs in the two samples are shown in Table 2. The crude mean SE was $0.87 \mathrm{D}$ and $-0.27 \mathrm{D}$ while the mean AL was $22.64 \mathrm{~mm}$ and $23.59 \mathrm{~mm}$ in grade 1 and grade 7 students, respectively. The distribution of SE was skewed towards more myopic values in both cohorts and neither SEs nor ALs were normally distributed (all P for Kolmogorov-Smirnov test $<0.001$ ).

Table 3 compares the prevalence of myopia ( $\mathrm{SE}<-0.5 \mathrm{D}$ ), high myopia $(\mathrm{SE}<-5.0 \mathrm{D})$ and mean ALs between the two samples. Grade 7 students had a higher prevalence of myopia $(29.4 \%$ vs. $2.4 \% ; P<0.001)$ and high myopia $(0.4 \%$ vs. $0.1 \% ; P<0.001)$ compared with grade 1 students. Grade 7 students also had longer ALs $(23.50 \mathrm{~mm}$ vs. $23.37 \mathrm{~mm} ; p$ $=0.004)$ after adjusting for the effect of gender, height and other myopia-related risk factors.

Finally, we estimated the reduction in odds of myopia associated with grade 7 students with adjustment of myopia-related factors. Adjustment for time spent on reading and writing after school per day led to a reduction in the excess prevalence of myopia in grade 7 students by
15.1\%. In addition, adjustment for time outdoors reduced the excess prevalence of myopia in grade 7 students by $33.4 \%$. Adjustment for other myopia-related variables did not significantly increase or reduce the excess prevalence of myopia in grade 7 students. (Table 4).

\section{Discussion}

In this school-based study of two samples with a difference in age of about 6 years, we reported a relatively lower prevalence of myopia in grade 1 and grade 7 students in rural China. We also found that approximately one-third of the excess prevalence of myopia in grade 7 students was explained by the reduction in time outdoors. Our study suggests that environmental factors such as time spent outdoors may play a major role in the development of school myopia in Chinese children.

High prevalence of myopia has been observed in many Chinese communities such as Shanghai [26], Guangzhou [27], Singapore [28], Hong Kong [29] and Taiwan [30]. Even in some rural areas in China, high prevalence of myopia was also reported among school-aged children [31, 32]. Thus, Chinese communities are regarded to have a prevailing concept of an "epidemic" of myopia [33]. However, it is still debatable whether the high prevalence is merely driven by environmental exposures associated with Chinese specific cultures. Our study found that myopes were very few among grade 1 students who have not been exposed to myopigenic factors such as spending large amounts of time on near work activities and less time outdoors. The prevalence of myopia among grade 1 students in our study is comparable to many other Asian communities which are characterized with low prevalence of myopia such as Cambodia [34], Laos [35] and Nepal [36]. Nowadays, most Chinese children in urban cities attend preschools such as kindergartens or childcare centers, and the syllabus in these settings is

Table 2 Distributions of cylindrical value, spherical value, axial length and spherical equivalent refraction among grade 1 and 7 samples

\begin{tabular}{|c|c|c|c|c|c|c|c|c|}
\hline & Mean & Median & Standard error & $\begin{array}{l}\text { Standard deviation } \\
\text { (Diopter) }\end{array}$ & Skewness & Kurtosis & $\begin{array}{l}\text { Inter Quartile } \\
\text { Range (Diopter) }\end{array}$ & $\begin{array}{l}\text { Kolmogorov-Smirnov } \\
\text { test }\end{array}$ \\
\hline \multicolumn{9}{|l|}{ Grade 1 sample } \\
\hline Cylindrical value (D) & -0.27 & -0.25 & 0.01 & 0.35 & -3.91 & 25.51 & 0.25 & $<0.001$ \\
\hline Spherical value (D) & 1.01 & 1.00 & 0.01 & 0.71 & -0.17 & 30.87 & 0.50 & $<0.001$ \\
\hline Axial length (mm) & 22.64 & 22.65 & 0.01 & 0.69 & 0.10 & 0.74 & 0.89 & $<0.001$ \\
\hline Spherical equivalent (D) & 0.87 & 0.88 & 0.01 & 0.68 & -1.37 & 40.46 & 0.50 & $<0.001$ \\
\hline \multicolumn{9}{|l|}{ Grade 7 sample } \\
\hline Cylindrical value (D) & -0.36 & -0.25 & 0.01 & 0.39 & -5.88 & 66.64 & 0.25 & $<0.001$ \\
\hline Spherical value (D) & -0.09 & 0.25 & 0.03 & 1.43 & -1.53 & 6.12 & 1.25 & $<0.001$ \\
\hline Axial length (mm) & 23.59 & 23.51 & 0.02 & 0.90 & 0.52 & 0.80 & 1.12 & $<0.001$ \\
\hline Spherical equivalent (D) & -0.27 & 0.15 & 0.03 & 1.46 & -1.69 & 6.27 & 1.38 & $<0.001$ \\
\hline
\end{tabular}


Table 3 Prevalence of myopia, high myopia, mean spherical equivalent and axial length in grade 1 and grade 7 samples

\begin{tabular}{|c|c|c|c|}
\hline & $\begin{array}{l}\text { Grade } 1 \text { Sample } \\
(n=2432)\end{array}$ & $\begin{array}{l}\text { Grade } 7 \text { Sample } \\
(n=2346)\end{array}$ & $P$ \\
\hline \multicolumn{4}{|l|}{$\begin{array}{l}\text { Prevalence of myopia } \\
(\mathrm{SE}<-0.5 \mathrm{D})(\%)\end{array}$} \\
\hline Sex adjusted & $2.4(1.1-3.7)$ & $29.4(28.1-30.8)$ & $<0.001$ \\
\hline \multicolumn{4}{|l|}{$\begin{array}{l}\text { Prevalence of high myopia } \\
(\mathrm{SE}<-6.0 \mathrm{D})(\%)\end{array}$} \\
\hline Sex adjusted & $0.1(0.0-0.3)$ & $0.4(0.2-0.6)$ & $<0.001$ \\
\hline \multicolumn{4}{|l|}{ Spherical equivalent (D) } \\
\hline Sex adjusted & $0.87(0.82-0.91)$ & $-0.27(-0.32--0.22)$ & $<0.001$ \\
\hline Multivariate adjusted $^{a}$ & $0.59(0.37-0.80)$ & $-0.24(-0.31--0.17)$ & $<0.001$ \\
\hline \multicolumn{4}{|l|}{ Axial length (mm) } \\
\hline Sex adjusted & $22.64(22.61-22.67)$ & $23.60(23.57-23.63)$ & $<0.001$ \\
\hline Multivariate adjusted ${ }^{a}$ & 23.07 (22.94-23.20) & $23.51(23.47-23.55)$ & $<0.001$ \\
\hline
\end{tabular}

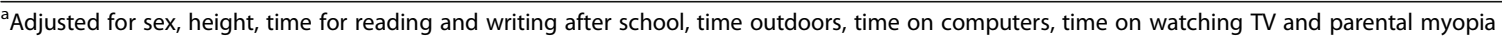

structured and vigorous, often being integrated with information technologies. Exposure to such a schooling system at an early age may result in an early onset of myopia. Even preschooling in urban China is highly competitive, academically oriented and emphasizes on very early educational achievements. The situation in our study site is different from most in other areas. For example, based on the survey results, most study participants have not attended preschools. Therefore, it is possible that our study participants were under less education 'pressure' than their counterparts in other areas, especially in urban cities. This may reflect a combination of lower level of reading exposures and nearwork loads, and corresponding higher levels of time outdoors. Although our study indicated that grade 7 students who have completed the primary school had a much higher prevalence of myopia compared with grade 1 students, the estimate was much lower compared with many reported in other studies of

Table 4 Effect of potential explanatory factors on the excess prevalence of myopia in grade 7 sample compared with grade 1 sample

\begin{tabular}{lllll}
\hline Model & \multicolumn{3}{l}{ Myopia(SE $<-0.5 \mathrm{D})$} \\
\cline { 2 - 5 } & OR & $95 \% \mathrm{Cl}$ & $\mathrm{P}$ & $\begin{array}{l}\text { \% Reduction } \\
\text { excess prevalence }\end{array}$ \\
\hline 1 & 18.22 & $13.74-24.16$ & $<0.001$ & Reference model \\
2 & 19.93 & $14.94-26.58$ & $<0.001$ & -9.9 \\
3 & 17.96 & $13.51-23.88$ & $<0.001$ & 15.1 \\
4 & 12.47 & $7.39-21.05$ & $<0.001$ & 33.4 \\
5 & 19.09 & $14.27-25.55$ & 0.012 & -5.1 \\
6 & 15.54 & $8.73-27.66$ & $<0.001$ & 34.7 \\
\hline
\end{tabular}

Model 1:sex; model 2:sex and parental myopia; model 3:sex and reading and writing per day after school; model 4: sex and time outdoors per day; model 5:sex and playing games or using computer; model 6:sex, parental myopia, reading and writing per day after school, time outdoors per day, playing games or using computer

$O R$ odds ratio, $\mathrm{Cl}$ confidence interval similar ages. Therefore, our findings emphasized the importance of the environmental impacts on school myopia.

Our study also revealed that there were little children with high myopia in both cohorts. This may be explained by the traditional view that genetic factors might have greater impact on high or extreme myopia while environmental factors may play a more important role in mild or moderate myopia. However, this argument is challenged given the recent rise in the prevalence of high myopia [26], which must have an environmental explanation. Further studies are need to distinguish between "old" high myopia, when educational pressures were low and is probably genetic, and "new" high myopia which has increased rapidly in younger cohorts, which is probably environmentally driven.

The implications of the findings in this study might be discussed. Although myopia prevalence was much higher among grade 7 students compared with grade 1 students, a $33 \%$ of the excess prevalence was due to reduction in time outdoors on the older cohort. We think that this is not sufficient to turn around the myopia epidemic in many of Asian communities, but the result suggests that general application of outdoor intervention during primary schooling might reduce the prevalence of myopia from over $80-90$ to $50-60 \%$ in many Asian communities characterized with an extremely high prevalence of myopia. This reduction is clinically significant and may also reduce the burden of pathologic myopia morbidities. While the effect of outdoor intervention on the protection of school myopia has been confirmed [37], the cost-effectiveness of outdoor programs integrated within school curriculums to prevent myopia should be evaluated.

The strength of the study included a large sample size, standardized measurement of refractive error and the inclusion of two samples with different ages. There were some limitations of the study, which need to be acknowledged. 
First, the study is a school-based study rather than a population-based one. The prevalence estimates might be distorted as children who dropped out of schools were not included. However, school attendance rates of students in 2015 in Mojiang were about 99\% due to the compulsory education system in China. Thus, we expected that the non-responder bias is minimal. Second, information on risk factors was collected by questionnaires, which might be potentially inaccurate due to recall biases. Finally, myopia-related risk factors included in this study could only explain about one-third of the excess prevalence of myopia in the older cohort and a large proportion of the excess prevalence might be captured by other factors which was not captured in this study.

\section{Conclusion}

In conclusion, this study reported relatively lower prevalence estimates of myopia and high myopia in a Chinese population. Our study suggests that generation-specific environmental exposures may play a major role in the increasing prevalence of myopia between different generations. Further studies are needed to understand the detailed environmental and lifestyle changes which underline the risk of myopia between generations.

\section{Abbreviations}

AL: Axial length; Cl: Confidence interval; D: Diopters; OR: Odds ratio; SE: spherical equivalent

\section{Funding}

This study was funded by the National Natural Science Foundation of China under grant no. 81773449 and grant no. 81560169 . The funders had no role in study design, data collection and analysis, decision to publish, or preparation of the manuscript.

\section{Availability of data and materials}

The datasets analyzed in this study are available from the corresponding author (Hua Zhong, zhoculist@163.com) upon reasonable request.

\section{Authors' contributions}

CWP and $\mathrm{HZ}$ designed the study. CWP, RKW, JL and $\mathrm{HZ}$ performed the research. CWP and RKW analyzed the data and wrote the paper. CWP and $\mathrm{HZ}$ supervised the study. All authors read and approved the final manuscript.

\section{Ethics approval and consent to participate}

Ethics committee approval was obtained from the Institutional Review Board of Kunming Medical University. We carried out the study according to the tenets of the Declaration of Helsinki involving human participants and the approved guidelines. Additionally, we obtained written informed consents from at least one parent or legal guardian of each participant.

\section{Competing interests}

The authors declare that they have no competing interests.

\section{Publisher's Note}

Springer Nature remains neutral with regard to jurisdictional claims in published maps and institutional affiliations.

\section{Author details}

'School of Public Health, Medical College of Soochow University, Suzhou, China. ${ }^{2}$ Department of Ophthalmology, the Second People's Hospital of Yunnan Province, Kunming, China. ${ }^{3}$ Department of Ophthalmology, the First
Affiliated Hospital of Kunming Medical University, 295 Xi Chang Road, Kunming 650032, China.

Received: 9 March 2018 Accepted: 30 May 2018

Published online: 11 June 2018

\section{References}

1. Pan CW, Ramamurthy D, Saw SM. Worldwide prevalence and risk factors for myopia. Ophthalmic Physiol Opt. 2012;32(1):3-16.

2. Holden BA, Fricke TR, Wilson DA, Jong M, Naidoo KS, Sankaridurg P, Wong TY, Naduvilath TJ, Resnikoff S. Global prevalence of myopia and high myopia and temporal trends from 2000 through 2050 Ophthalmology. 2016;123(5):1036-42.

3. Morgan IG, Ohno-Matsui K, Saw SM. Myopia. Lancet. 2012;379(9827):1739-48

4. Rose KA, Morgan IG, Smith W, Burlutsky G, Mitchell P, Saw SM. Myopia, lifestyle, and schooling in students of Chinese ethnicity in Singapore and Sydney. Arch Ophthalmol. 2008;126(4):527-30.

5. Wu HM, Seet B, Yap EP, Saw SM, Lim TH, Chia KS. Does education explain ethnic differences in myopia prevalence? A population-based study of young adult males in Singapore. Optom Vis Sci. 2001;78(4):234-9.

6. Pan CW, Zheng YF, Anuar AR, Chew M, Gazzard G, Aung T, Cheng CY, Wong TY, Saw SM. Prevalence of refractive errors in a multiethnic Asian population: the Singapore epidemiology of eye disease study. Invest Ophthalmol Vis Sci. 2013:54(4):2590-8

7. Pan CW, Klein BE, Cotch MF, Shrager S, Klein R, Folsom A, Kronmal R, Shea SJ, Burke GL, Saw SM, et al. Racial variations in the prevalence of refractive errors in the United States: the multi-ethnic study of atherosclerosis. Am J Ophthalmol. 2013;155(6):1129-38. e1121

8. Morgan I, Rose K. How genetic is school myopia? Prog Retin Eye Res. 2005:24(1):1-38.

9. Lin Z, Vasudevan B, Jhanji V, Mao GY, Gao TY, Wang FH, Rong SS, Ciuffreda KJ, Liang YB. Near work, outdoor activity, and their association with refractive error. Optometry Vision Sci. 2014;91(4):376-82.

10. Liang YB, Lin Z, Vasudevan B, Jhanji V, Young A, Gao TY, Rong SS, Wang NL, Ciuffreda KJ. Generational difference of refractive error in the baseline study of the Beijing myopia progression study. Brit J Ophthalmol. 2013;97(6):765-9.

11. Zhang Q, Guo X, Xiao X, Jia X, Li S, Hejtmancik JF. A new locus for autosomal dominant high myopia maps to 4q22-q27 between D4S1578 and D4S1612. Mol Vis. 2005;11:554-60.

12. Zhang Q, Guo X, Xiao X, Jia X, Li S, Hejtmancik JF. Novel locus for X linked recessive high myopia maps to Xq23-q25 but outside MYP1. J Med Genet. 2006:43(5):e20.

13. Tran-Viet KN, Powell C, Barathi VA, Klemm T, Maurer-Stroh S, Limviphuvadh V, Soler V, Ho C, Yanovitch T, Schneider G, et al. Mutations in SCO2 are associated with autosomal-dominant high-grade myopia. Am J Hum Genet. 2013;92(5):820-6.

14. Yang Z, Xiao X, Li S, Zhang Q. Clinical and linkage study on a consanguineous Chinese family with autosomal recessive high myopia. Mol Vis. 2009:15:312-8.

15. Ma JH, Shen SH, Zhang GW, Zhao DS, Xu C, Pan CM, Jiang H, Wang ZQ, Song HD. Identification of a locus for autosomal dominant high myopia on chromosome 5p13.3-p15.1 in a Chinese family. Mol Vis. 2010;16:2043-54.

16. Rong SS, Chen LJ, Pang CP. Myopia genetics-the Asia-Pacific perspective. Asia-Pacific journal of ophthalmology. 2016;5(4):236-44.

17. Pan CW, Qiu OX, Qian DJ, Hu DN, Li J, Saw SM, Zhong H. Iris colour in relation to myopia among Chinese school-aged children. Ophthalmic Physiol Opt. 2018;38(1):48-55.

18. Pan CW, Wu RK, Liu H, Li J, Zhong H. Types of lamp for homework and myopia among Chinese school-aged children. Ophthalmic Epidemiol. 2017:1-7.

19. Pan CW, Wu RK, Wang P, Li J, Zhong H. Reduced vision, refractive errors and health-related quality of life among adolescents in rural China. Clin Exp Optom. 2018;

20. Luo HD, Gazzard G, Liang Y, Shankar A, Tan DT, Saw SM. Defining myopia using refractive error and uncorrected logMAR visual acuity $>0.3$ from 1334 Singapore school children ages 7-9 years. Br J Ophthalmol. 2006;90(3):362-6.

21. Qian DJ, Zhong H, Li J, Niu Z, Yuan Y, Pan CW. Myopia among school students in rural China (Yunnan). Ophthalmic Physiol Opt. 2016;36(4):381-7.

22. Li SM, Liu LR, Li SY, Ji YZ, Fu J, Wang Y, Li H, Zhu BD, Yang Z, Li L, et al. Design, methodology and baseline data of a school-based cohort study in Central China: the Anyang childhood eye study. Ophthalmic Epidemiol. 2013;20(6):348-59. 
23. Wu JF, Bi HS, Wang SM, Hu YY, Wu H, Sun W, Lu TL, Wang XR, Jonas JB. Refractive error, visual acuity and causes of vision loss in children in Shandong, China. The Shandong children eye study. PLoS One. 2013;8(12):e82763.

24. Pan CW, Zheng YF, Wong TY, Lavanya R, Wu RY, Gazzard G, Saw SM. Variation in prevalence of myopia between generations of migrant indians living in Singapore. Am J Ophthalmol. 2012;154(2):376-81. e371

25. Wong TY, Klein R, Duncan BB, Nieto FJ, Klein BE, Couper DJ, Hubbard LD, Sharrett AR. Racial differences in the prevalence of hypertensive retinopathy. Hypertension. 2003;41(5):1086-91.

26. Sun J, Zhou J, Zhao P, Lian J, Zhu H, Zhou Y, Sun Y, Wang Y, Zhao L, Wei Y, et al. High prevalence of myopia and high myopia in 5060 Chinese university students in shanghai. Invest Ophthalmol Vis Sci. 2012;53(12):7504-9.

27. He M, Zeng J, Liu Y, Xu J, Pokharel GP, Ellwein LB. Refractive error and visual impairment in urban children in southern China. Invest Ophthalmol Vis Sci. 2004;45(3):793-9.

28. Au Eong KG, Tay TH, Lim MK. Education and myopia in 110,236 young Singaporean males. Singap Med J. 1993;34(6):489-92.

29. Edwards MH, Lam CS. The epidemiology of myopia in Hong Kong. Ann Acad Med Singap. 2004;33(1):34-8.

30. Lin LL, Shih YF, Hsiao CK, Chen CJ. Prevalence of myopia in Taiwanese schoolchildren: 1983 to 2000. Ann Acad Med Singap. 2004;33(1):27-33.

31. Guo $K$, Yang $d Y$, Wang $Y$, Yang $X R$, Jing $X X$, Guo $Y Y$, Zhu D, You QS, Tao $Y$, Jonas JB. Prevalence of myopia in schoolchildren in Ejina: the Gobi Desert children eye study. Invest Ophthalmol Vis Sci. 2015;56(3):1769-74.

32. He $M$, Huang $W$, Zheng $Y$, Huang $L$, Ellwein $L B$. Refractive error and visual impairment in school children in rural southern China. Ophthalmology. 2007;114(2):374-82.

33. Saw SM. A synopsis of the prevalence rates and environmental risk factors for myopia. Clin Exp Optom. 2003;86(5):289-94.

34. Gao Z, Meng N, Muecke J, Chan WO, Piseth H, Kong A Jnguyenphamhh T, Dehghan Y, Selva D, Casson R, et al. Refractive error in school children in an urban and rural setting in Cambodia. Ophthalmic Epidemiol. 2012;19(1):16-22.

35. Casson RJ, Kahawita S, Kong A, Muecke J, Sisaleumsak S, Visonnavong V. Exceptionally low prevalence of refractive error and visual impairment in schoolchildren from Lao People's Democratic Republic. Ophthalmology. 2012;119(10):2021-7.

36. Pokharel GP, Negrel AD, Munoz SR, Ellwein LB. Refractive error study in children: results from Mechi zone, Nepal. Am J Ophthalmol. 2000;129(4):436-44.

37. He M, Xiang F, Zeng Y, Mai J, Chen Q, Zhang J, Smith W, Rose K, Morgan IG. Effect of time spent outdoors at school on the development of myopia among children in China: a randomized clinical trial. JAMA. 2015;314(11):1142-8.

\section{Ready to submit your research? Choose BMC and benefit from:}

- fast, convenient online submission

- thorough peer review by experienced researchers in your field

- rapid publication on acceptance

- support for research data, including large and complex data types

- gold Open Access which fosters wider collaboration and increased citations

- maximum visibility for your research: over $100 \mathrm{M}$ website views per year

At BMC, research is always in progress.

Learn more biomedcentral.com/submissions 